\title{
A case of Fahr's disease presenting with anxiety disorder: Magnetic resonance spectroscopy findings
}

Article in Internet Journal of Neurology · January 2010

CITATIONS

0

5 authors, including:

\section{Rahmi Cubuk}

Maltepe University

52 PUBLICATIONS 195 CITATIONS

SEE PROFILE

Nilgun Cinar

Maltepe University

94 PUBLICATIONS 41 CITATIONS

SEE PROFILE
Sevki Sahin

Maltepe University

137 PUBLICATIONS 211 CITATIONS

SEE PROFILE

Some of the authors of this publication are also working on these related projects: 


\title{
A Case of Fahr's Disease Presenting with Anxiety Disorder: Magnetic Resonance Spectroscopy Findings
}

\author{
C R, S S, T N, C N, C A
}

\section{Citation}

C R, S S, T N, C N, C A. A Case of Fahr's Disease Presenting with Anxiety Disorder: Magnetic Resonance Spectroscopy Findings. The Internet Journal of Neurology. 2009 Volume 12 Number 2.

\begin{abstract}
Fahr's disease involves calcification of basal ganglia and dentate nuclei of the cerebellum. Radiologic features of Fahr's disease including computed tomography and magnetic resonance imaging are well described in the present literature. To our knowledge, magnetic resonance spectroscopy findings are not described yet. We report a case Fahr's disease presenting with symptoms of anxiety disorder with detailed radiological survey including single voxel magnetic resonance spectroscopy analysis.
\end{abstract}

\section{CASE REPORT}

A 41-year-old, right-handed man was admitted to the psychiatry clinic in our hospital suffering from progressing anxiety and sleep disorders associated with paranoid behaviors. Neurological examination showed no abnormality in motor and sensorial functions as well as the cerebellary system. Deep tendon reflexes were thought to be hyperactive. Neither pyramidal irritatition nor ekstrapiramidal system disorder was observed. Despite his Mini-Mental Status Examination (MMSE) test was found in normal limits, his Beck Anxiety Inventory (BAI) score was 43 (maximum score: 63). Laboratory tests, including serum phosphorus, calcium, vitamin D and parathyroid hormone levels were within the normal limits. Routine hematological and urine tests were also normal. Computed tomography (CT) scan prominently revealed hyperdensities in the basal ganglia, thalamic nuclei, and cerebral and in the cerebellar white matter which correspond to calcifications (Figure 1ab).

\section{Figure 1}

Figure 1. () There are hyperdensities in the basal ganglia thalamic nuclei and () cerebral white matter that correspond to calcifications at $\mathrm{CT}$ scan

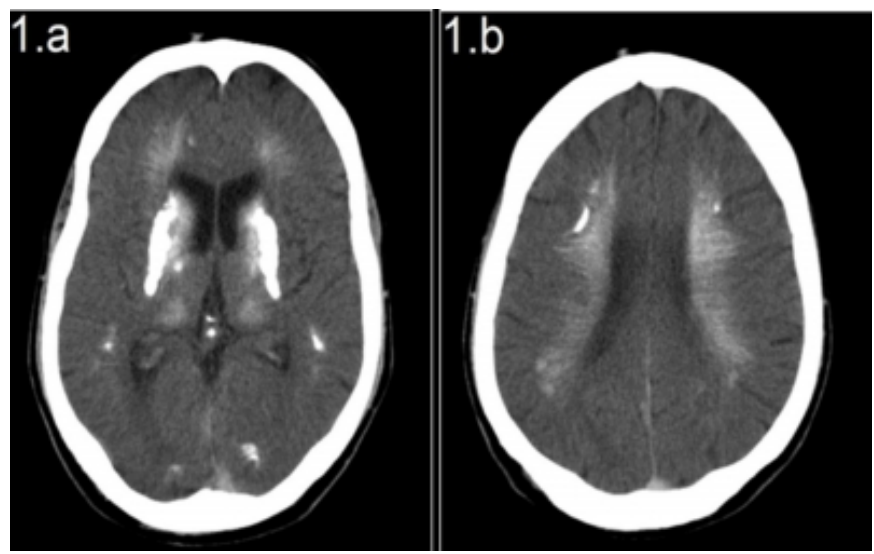

These areas of basal ganglia and thalami showed hyperintensity bilaterally at axial T1-weighted magnetic resonance images (MRI) whereas, axial T2-weighted MRI manifest hypointensity in the same areas (Figure 2a). Additionally, at T2-weighted MRI periventricular areas were hyperintense, which was considered to be secondary to gliosis (Figure 2b). 


\section{Figure 2}

Figure 2. These areas of basal ganglia and thalami were hypointense bilaterally at axial T2-weighted MR imaging (). T2-weighted MR image also shows hyperintensity at periventricular areas ).

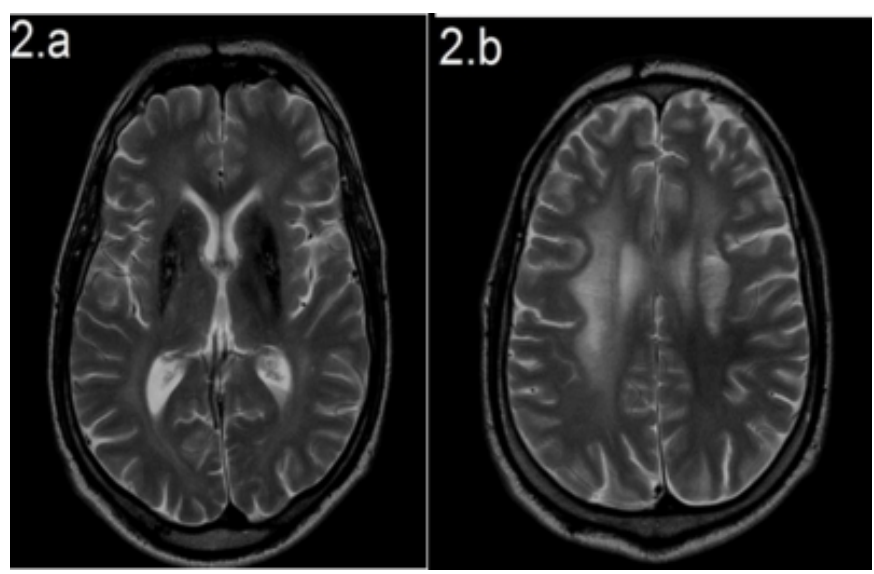

Single-voxel proton magnetic resonance spectroscopy (MRS) (Short TE: 140ms) was performed on the right centrum semiovale and basal ganglion. The MRS findings encountered gliotic changes with the decrease in all metabolic levels in the sentrum semiovale where hyperintensity were detected at $\mathrm{T} 2$ weighted images (Figure $3)$.

\section{Figure 3}

Figure 3. Single-voxel proton MR spectroscopy image shows decrease in all metabolic levels on the right centrum semiovale

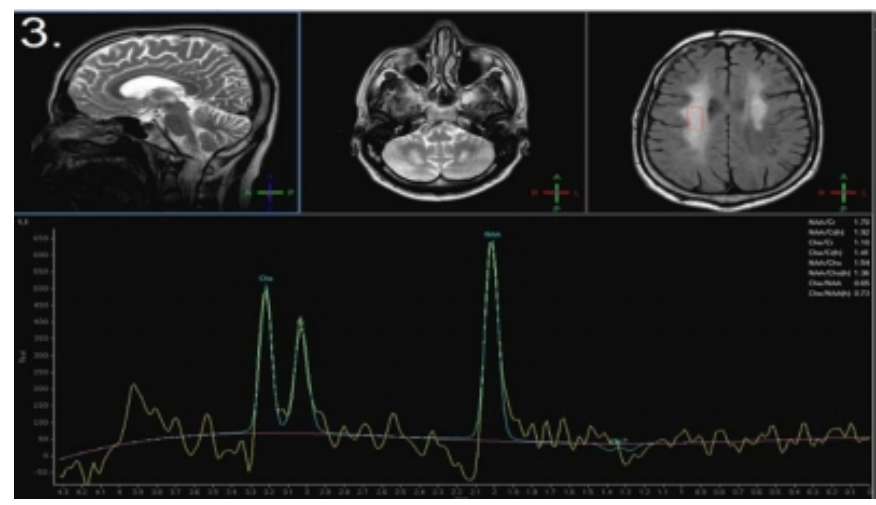

MRS trace showed no diagnostic value in the left basal ganglion. Probably, MRI spectrometric parameters were corrupted due to the calcifications in the left basal ganglion. Based on physical examination, laboratory tests, imaging findings including CT, MRI and MRS Fahr's disease was diagnosed. We started him on olanzapine $10 \mathrm{mg} /$ day and paroxetine $20 \mathrm{mg} /$ day as symptomatic treatment. During the 6 months of follow-up period, his psychiatric condition gradually improved.

\section{DISCUSSION}

Idiopathic calcification of the basal ganglia, also known as Fahr's disease, is a rare neurologic disorder of unknown etiology characterized by neuropsychiatric abnormalities, Parkinsonian or choreoathetotic-type movement disturbance, and extensive symmetrical calcification of the basal ganglia and dentate nuclei in the cerebellum (1). These symptoms cannot be explained by any other particular disorder of the calcium phosphorus metabolism or any other disease (2). Dementia is a well-recognized neuropsychiatric manifestation of Fahr's disease. In addition, a schizophrenialike psychosis characterized by paranoia, hallucinations, and delusions has been reported (1). Although our case's MMSE score was found in normal limits, his BAI score was suggested the severe anxiety level.

The pathophysiology of psychosis in Fahr's disease remains unknown, though previous studies have found a decreased cerebral blood flow matching the distribution of calcification or decreased perfusion in the cortex, which may reflect secondary deficits due to calcification $(3,4)$. Some reported psychiatric manifestations of Fahr's disease and its neuroimaging findings in current literature also summarized in Table $1(3,5,6,7,8)$.

\section{Figure 4}

Table 1. Some reported psychiatric manifestations of Fahr's disease and its cerebral findings in current literarure.

\begin{tabular}{|l|c|l|l|}
\hline Author & $\begin{array}{l}\text { Age/ } \\
\text { Sex }\end{array}$ & Neuroimaging Findings & Symptom/Diagnose \\
\hline $\begin{array}{l}\text { Benke et aL. } \\
2004^{5}\end{array}$ & $50 / \mathrm{M}$ & $\begin{array}{l}\text { Basal ganglia and frontal } \\
\text { lobe }\end{array}$ & Subacute dementia \\
\hline $\begin{array}{l}\text { Shouyama et } \\
\text { al. 2005 }\end{array}$ & $32 / \mathrm{F}$ & Basal ganglia and thalamus & $\begin{array}{l}\text { Schizophrenia-like } \\
\text { psychosis }\end{array}$ \\
\hline $\begin{array}{l}\text { Cartier et al. } \\
2002^{6}\end{array}$ & $\begin{array}{l}55- \\
56- \\
58 / \mathrm{F}\end{array}$ & $\begin{array}{l}\text { Cerebellum, brain- } \\
\text { stemlenticular nuclei, } \\
\text { thalami and semioval } \\
\text { centers }\end{array}$ & $\begin{array}{l}\text { Subcortical } \\
\text { dementia }\end{array}$ \\
\hline $\begin{array}{l}\text { Kümmer et al. } \\
2006^{7}\end{array}$ & $\begin{array}{c}40 / \\
\text { Basal ganglia and the } \\
\text { fronto-parietal subcortical } \\
\text { area }\end{array}$ & $\begin{array}{l}\text { Depressive disorder, } \\
\text { stereotyped } \\
\text { behaviors }\end{array}$ \\
\hline $\begin{array}{l}\text { Ilievski et al. } \\
2002^{8}\end{array}$ & $73 / \mathrm{F}$ & $\begin{array}{l}\text { Basal ganglia } \\
\text { Paranoid } \\
\text { schizophrenia }\end{array}$ \\
\hline
\end{tabular}

In Fahr's disease symmetrical amorphous calcifications are detected at basal ganglia, cerebral and cerebellar white matter and dentate nuclei bilaterally in CT examinations. Additionally, no contrast enhancement is found in theses areas (9). Usually, calcium are hyperintense on T1W MRI images whereas, varying signal intensities of calcified lesions detected on MRI are related to stage of disease and the volume of calcium deposit. Single-voxel proton MRS was performed on the right centrum semiovale and bilateral basal ganglia. The MRS findings encountered gliotic changes with the decrease in all metabolic levels in the 
sentrum semiovale where hyperintensity were detected at T2 weighted images (Fig. 3a). MRS trace showed no diagnostic value in the left basal ganglia. Probably, MRI spectrometric parameters were corrupted due to the calcifications in the left basal ganglia.

We report a case Fahr's disease presenting with symptoms of anxiety disorder with detailed radiological survey including single voksel MRS analysis. Radiologic features of Fahr's disease including CT and MRI are well described in the present literature. Despite, these findings could not support a specific diagnosis of Fahr's disease; we report here that for its MRS findings have not been previously described.

\section{References}

1. Cummings JL, Gosenfeld LF, Houlihan JP, McCaffrey T. Neuropsychiatric disturbances associated with idiopathic calcification of the basal ganglia. Biol Psychiatry 1983; 18:591-601.
2. Modrego PJ, Mojonero J, Serrano M, Fayed N. Fahr's syndrome presenting with pure and progressive presenile dementia. Neurol Sci 2005;26:367-369.

3. Shoyama M, Kitabata Y, Kaku T, Shinosaki K.

Evaluation of regional cerebral blood flow in fahr disease with schizophrenia-like psychosis: a case report. Am J Neuroradiol. 2005;26:2527-2529.

4. Hempel A, Henze M, Berghoff C, Garcia N, Ody R, Schröder J. PET findings and neuropsychological deficits in a case of Fahr's disease. Psychiatry Res. 2001;108:133-40.

5. Benke T, Karner E, Seppi K, Delazer M, Marksteiner J, Donnemiller E. Subacute dementia and imaging correlates in a case of Fahr's disease. J Neurol Neurosurg Psychiatry. 2004;75(8):1163-1165.

6. Cartier L, Passig C, Gormaz A, López J. Rev Med Chil. Neuropsychological and neurophysiological features of Fahr's disease. 2002;130(12):1383-1390.

7. Kümmer A, de Castro M, Caramelli P, Cardoso F, Teixeira AL. Severe behavioral changes in a patient with Fahr's disease. Arq Neuropsiquiatr. 2006;64:645-649. 8. Ilievski, K Rodzevski, M Gibbon, AJ Dwork. Fahr's Disease and Schizophrenia in a Patient With Secondary Hypoparathyroidism. J Neuropsychiatry Clin Neurosci 2002;14:357-358.

9. Scotti G, Scialfa G, Tampieri D, Landoni L. MR imaging in Fahr disease. J Comput Assist Tomogr 1985; 9: 790-792. 


\section{Author Information}

Cubuk R

Department of Radiology, Faculty of Medicine, Maltepe University

\section{Sahin S}

Department of Neurology, Faculty of Medicine, Maltepe University

\section{Tasali $\mathbf{N}$}

Department of Radiology, Faculty of Medicine, Maltepe University

\section{Cinar N}

Department of Neurology, Faculty of Medicine, Maltepe University

\section{Cubuk A}

Department of Neurology, Medicana Hospital 